\title{
Safety and Efficacy of Exclusive Enteral Nutrition for Percutaneously Undrainable Abdominal Abscesses in Crohn's Disease
}

\author{
Yibin Zhu, ${ }^{1}$ Liang Xu, ${ }^{1}$ Wei Liu, ${ }^{1}$ Weilin Qi, ${ }^{1}$ Qian Cao, ${ }^{2,3}$ and Wei Zhou ${ }^{1,2}$ \\ ${ }^{1}$ Department of General Surgery, Sir Run Run Shaw Hospital, School of Medicine Zhejiang University, Hangzhou, China \\ ${ }^{2}$ Inflammatory Bowel Disease Center, Sir Run Run Shaw Hospital, School of Medicine Zhejiang University, Hangzhou, China \\ ${ }^{3}$ Department of Gastroenterology, Sir Run Run Shaw Hospital, School of Medicine, Zhejiang University, Hangzhou, China
}

Correspondence should be addressed to Wei Zhou; nuzwlvran@aliyun.com

Received 16 June 2017; Revised 27 July 2017; Accepted 3 August 2017; Published 30 August 2017

Academic Editor: Fernando A. M. Herbella

Copyright (c) 2017 Yibin Zhu et al. This is an open access article distributed under the Creative Commons Attribution License, which permits unrestricted use, distribution, and reproduction in any medium, provided the original work is properly cited.

\begin{abstract}
Background. The percutaneously undrainable abdominal abscesses in Crohn's disease (CD) are not uncommon. The treatment protocol is still under debate. This study was conducted to assess the safety and efficacy of exclusive enteral nutrition (EEN) for percutaneously undrainable abscesses in CD. Methods. A consecutive cohort of 83 CD patients with percutaneously undrainable abdominal abscesses between January 2011 and June 2015 was retrospectively analyzed. They were divided into the EEN group and the non-EEN group. Results. The cumulative surgical rate was significantly lower in the EEN group than in the non-EEN group $(P=0.001)$. Fifteen percent patients treated with EEN avoided surgery. EEN $(P=0.002)$ was associated with a decreased need for surgery. Previous abdominal surgery $(P=0.009)$ and abscess diameter $>3 \mathrm{~cm} \quad(P=0.022)$ were associated with an increased need for operation. EEN increased the albumin level, while decreased ESR and CRP significantly for patients requiring surgery. The risk of postoperative intra-abdominal septic complications $(P=0.036)$ was significantly lower in the EEN group compared with the non-EEN group. Conclusions. EEN is feasible in $\mathrm{CD}$ patients presenting with percutaneously undrainable abdominal abscesses. It is associated with a reduction in surgical rate, optimized preoperative condition, and improved postoperative outcomes in these specific groups of patients.
\end{abstract}

\section{Introduction}

Crohn's disease (CD) is a chronic inflammatory disorder of the intestine including nonstricturing/nonpenetrating, stricturing, and penetrating disease phenotypes [1]. Penetrating disease may be complicated by abscess formation. This complication accounts for the high rate of surgery in patients with $\mathrm{CD}$. In the literature, occurrence rates for abdominal abscesses vary from 10 to $30 \%$ [2]. The common treatments include antibiotics, percutaneous or surgical drainage of fluid collections, bowel rest, and, eventually, resection of the diseased bowel. Nowadays, percutaneous drainage (PD) has been served as a bridging strategy before definitive surgery to reduce postoperative complications [3]. Patients with concomitant stenosis, enterocutaneous fistula, or refractory active disease are likely to require surgery.

Though PD has been increasingly used for well-defined and unilocular abscesses, occasionally, abscesses are not technically drainable for PD due to the difficult location or multilocular form [4], such as the patients with mesenteric and interloop abscesses, which were difficult to treat with PD. Under these circumstances, only antibiotics may be prescribed for patients, while steroids, immunosuppressants, and antitumor necrosis factor (anti-TNF) agents are avoided because of the potential for peritoneal and systemic infection [5]. For patients who do not respond to antibiotics, definite 
surgery or a defunctioning ostomy to cool down the abscesses is usually needed [6]. The patients then take the risk of more postoperative complications or repeated operations.

Exclusive enteral nutrition (EEN) is considered to be of great importance in patients with $\mathrm{CD}$, which provided the liquid nutrition formula to meet the daily nutritional requirements. In children with CD, the EEN is the first line therapy to treat active CD instead of corticosteroid [7, 8]. EEN has shown to be an effective and safe treatment option to induce remission of CD in adults [9]. A 4-week EEN treatment has the effect of improving health-related quality of life in adults with active CD [9]. However, use of EEN in patients with abscesses remains controversial because of the bowel rest principle for penetrating CD treatment. Only a few studies have formally evaluated the clinical outcomes of EEN in penetrating disease [10-12]. As far as we know, there were no published studies in the current literature which determined the effect of EEN on outcomes in CD patients with percutaneously undrainable abscesses. Therefore, the aim of this retrospective study was to specifically evaluate the following: (1) the safety of EEN for abdominal abscesses in $\mathrm{CD},(2)$ the surgical rate of these patients on EEN, and (3) the effect of EEN on preoperative optimization and postoperative outcomes.

\section{Materials and Methods}

2.1. Patients and Definitions. All the charts of consecutive CD patients from January 2011 to June 2015 in Sir Run Run Shaw Hospital were reviewed. An abscess was defined as an extraluminal ring enhancing fluid collection $1 \mathrm{~cm}$ or greater in diameter, identified on computed tomography (CT) or magnetic resonance imaging (MRI) [13]. Abscesses developed within one month after abdominal surgery were considered as postoperative complications and excluded. Accessibility of PD was discussed with surgeons and radiologists. CT or MRI was used to assess whether the abscess was subsided or not after treatment.

2.2. Patient Management. Treatments for the percutaneously undrainable abscesses were generally started with nutrition management and concomitant antibiotics. In the routine clinical practice at our inflammatory bowel disease (IBD) center, the patients presenting with percutaneously undrainable abdominal abscesses are recommended with EEN treatment. However, some patients failed to receive the EEN therapy because they can not tolerate the EEN or comply with the EEN therapy. Thus, in our study, the patients with well tolerance with the EEN or good compliance with the EEN therapy were assigned to the EEN group, while the patients with poor compliance or poor tolerance with the EEN therapy were assigned to the non-EEN group.

The EEN administered was a product of the Nutricia company (Wuxi, China) called Peptison liquid, which is composed of maltodextrin, whey protein hydrolysate, citric acid, vegetable oil, medium-chain triglyceride, vitamins, minerals, and trace elements. The content of the three major nutrients included 17.6 grams carbohydrate, 1.7 grams lipid, and 4 grams of protein per $100 \mathrm{~mL}$ liquid. The calorie density was $1 \mathrm{kcal} / \mathrm{mL}$ with an osmolarity of $440 \mathrm{mosm} / \mathrm{L}$. The elemental formula was taken continuously through a nasogastric tube by using an infusion pump. The dosage of EEN was gradually increased to the full dose in order to reduce side effects such as diarrhea and abdominal distension. The patients were recommended to use of EEN until abscess resolution or surgery. The daily calorie was $25-30 \mathrm{kcal} / \mathrm{kg}$ body weight. During the period of EEN, any other food or drink was forbidden except water. Antibiotics were discontinued when the patients' temperature and white blood cell count normalized. Surgery was indicated when the patients had no clinical improvement, persistent or recurrent abscesses, fistulas, or bowel obstruction.

2.3. Data Collection. The electronic medical records were accessed to retrieve the following information on eligible subjects: demographic data, date of CD diagnosis, date of abscess diagnosis, location and size of abscess, multiplicity of abscess, Montreal classification [1], previous CD-related abdominal surgery, laboratory and radiology tests, concurrent medical therapy, compliance of EEN therapy, abscess resolution rates, time to surgery, surgical procedure, stoma creation, postoperative complications, length of hospital stay after surgery, and length of follow-up. Postoperative intra-abdominal septic complications (IASCs) were defined as any anastomotic leak, intra-abdominal abscess, or enterocutaneous fistula that occurred within the first 30 days after surgery [14]. The primary outcome was the subsequent surgery. Secondary endpoints were postoperative IASCs and duration of hospitalization.

This study was approved by the institutional review board at Sir Run Run Shaw Hospital and was conducted in accordance with the Helsinki Declaration.

2.4. Statistical Analysis. Statistical analysis was performed with SPSS for Windows, version 19.0 (SPSS; Chicago, IL). Quantitative data were expressed as mean \pm SD or medians with ranges. Comparisons between groups were conducted using Student's $t$-test, Fisher's, or $\chi^{2}$ test. The cumulative surgical rate was estimated by the Kaplan-Meier approach and compared using the log-rank test. The predictors for surgery were evaluated by multivariate analysis using a Cox proportional hazards model. A $P<0.05$ was considered statistically significant.

\section{Results}

3.1. Patient Characteristics. Clinical characteristics of patients enrolled in the study are indicated in Table 1. According to the enroll criterion, we identified 83 patients with CD presenting with abscesses, which were considered technically unsuitable to PD because of the multilocular form or unfavorable abscess location with an extremely difficult or impossible access pathway to the abscess cavity. The mean age was $34.33 \pm 11.06$ years, ranging from 17 to 60 years. 47 of $83(56.6 \%)$ were males. The duration of CD ranged from 36 days to 30 years (median, 4.73 years).

According to Montreal classification, disease phenotypes were ileocolonic in $52(62.65 \%)$, colonic in $3(3.61 \%)$, and 
TABLE 1: Demographic and clinical characteristics of CD patients with percutaneously undrainable abscesses by the treatment group.

\begin{tabular}{|c|c|c|c|}
\hline Characteristics & EEN group $(n=54)$ & Non-EEN group $(n=29)$ & $P$ \\
\hline Gender, $n$ (male/female) & $32 / 22$ & $15 / 14$ & 0.509 \\
\hline Age at onset of abscess (y), median (range) & $32.8(17-51)$ & $37.1(17-60)$ & 0.094 \\
\hline Disease duration (y), median (range) & $4.3(0.16-30)$ & $5.5(0.1-20)$ & 0.274 \\
\hline Previous abdominal surgery, $n(\%)$ & $11(20.4)$ & $8(27.6)$ & 0.456 \\
\hline Montreal classification of age, $n(\%)$ & & & 0.526 \\
\hline A1 ( $<16$ years $)$ & $0(0)$ & $0(0)$ & \\
\hline A2 (17-40 years) & $39(72.2)$ & $19(65.5)$ & \\
\hline A3 (>40 years) & $15(27.8)$ & $10(34.5)$ & \\
\hline Montreal classification of disease location, $n(\%)$ & & & 1.000 \\
\hline L1 (ileal) & $18(33.3)$ & $10(34.5)$ & \\
\hline L2 (colonic) & $2(3.7)$ & $1(3.4)$ & \\
\hline L3 (ileocolonic) & $34(63.0)$ & $18(62.1)$ & \\
\hline Abscess location, $n(\%)$ & & & 0.574 \\
\hline Right lower quadrant & $24(44.4)$ & $13(44.8)$ & \\
\hline Pelvis & $18(33.3)$ & $7(24.1)$ & \\
\hline Others & $12(22.2)$ & $9(31.0)$ & \\
\hline Multiple abscesses, $n(\%)$ & $8(14.8)$ & $7(24.1)$ & 0.293 \\
\hline Abscess diameter $>3 \mathrm{~cm}, n(\%)$ & $11(11.1)$ & $11(24.1)$ & 0.084 \\
\hline Fistula, $n(\%)$ & $31(57.4)$ & $11(37.9)$ & 0.091 \\
\hline Perianal lesion, $n(\%)$ & $7(13.0)$ & $7(24.1)$ & 0.227 \\
\hline Steroids at diagnosis, $n(\%)$ & $18(33.3)$ & $14(48.3)$ & 0.182 \\
\hline AZA/6-MP at diagnosis, $n(\%)$ & $20(37.0)$ & $14(48.3)$ & 0.321 \\
\hline Infliximab at diagnosis, $n(\%)$ & $7(13.0)$ & $3(10.3)$ & 1.000 \\
\hline \multicolumn{4}{|l|}{ Laboratory indices } \\
\hline White blood cell $\left(\times 10^{9} / \mathrm{L}\right)$, mean, (range) & $8.8(3.6-15)$ & $7.1(2.7-11.6)$ & 0.012 \\
\hline Hemoglobin $(\mathrm{g} / \mathrm{L})$, mean (range) & $11.8(6.1-15.8)$ & $10.9(6.6-14.1)$ & 0.366 \\
\hline ESR $(\mathrm{mm} / \mathrm{h})$, mean (range) & $36.7(2-92)$ & $33.3(2-96)$ & 0.574 \\
\hline C-reactive protein $(\mathrm{mg} / \mathrm{L})$, mean (range) & $56.4(3.9-202.4)$ & $32.6(0.4-159)$ & 0.029 \\
\hline Albumin (g/L), mean (range) & $32.5(19.5-41.1)$ & $30.8(17-40.3)$ & 0.216 \\
\hline
\end{tabular}

ESR: erythrocyte sedimentation rate; EEN: exclusive enteral nutrition; AZA: azathioprine; 6-MP: mercaptopurine.

jejunoileal in $28(33.73 \%)$ patients. Previous CD-related abdominal surgery was reported in 19 (22.89\%) patients. According to the group definition, 54 patients were in the EEN group, and 29 patients were in the non-EEN group. The mean duration of EEN treatment was 5.9 weeks, ranging from 2 to 8 weeks. There were no severe adverse events that happened in both group. Patients' characteristics were mostly comparable in the EEN group and the non-EEN group as shown in Table 1 . However, C-reactive protein (CRP) levels $(P=0.029)$ and white blood cell (WBC) levels $(P=012)$ were significantly higher in the EEN group compared with the non-EEN group.

3.2. Cumulative Surgical Rate. The cutoff date of the followup for all participants was on January 31, 2017. The median follow-up period for the entire study group was 19.8 months, ranging from 3.0 to 65.3 months. There were no serious adverse events reported in all patients with EEN treatment. During the follow-up period, the estimated cumulative rates of surgery for CD patients with undrainable abscess were $43 \%$ at 1 month, $61 \%$ at 3 months, $85 \%$ at 1 year, and $90 \%$ at 2 years. The cumulative surgical rate was significantly lower in the EEN group than in the non-EEN group $(P=0.001$, Figure 1$)$. By the end of follow-up, 46 patients in the EEN group (78.8\%) and 28 patients in the non-EEN group (92.3\%) required surgery. Among which, 41 patients in the EEN group and 19 patient in the non-EEN group had abscess resolution $(P=0.023)$. The median length of time between onset of abscess and surgery was 39 days (range, 7 1000 days). 8 patients in the EEN group and 1 patient in the non-EEN group avoided surgery by the end of follow-up.

3.3. The Clinical Factors Associated with Surgery. The effects of categorical variables on the overall time to surgery were analyzed with the Kaplan-Meier method. The results of the log-rank tests for each categorical variable are presented in Table 2. Univariate analysis identified that EEN was associated with a decreased need for operation and 2 clinical variables associated with an increased need for operation: previous abdominal surgery and abscess diameter $>3 \mathrm{~cm}$. Age, gender, perianal disease, fistula, disease location and 


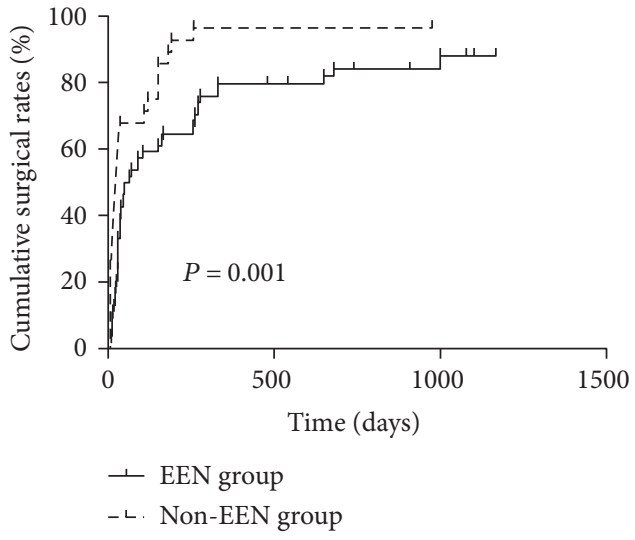

FIGURE 1: The cumulative surgical rate was significantly lower in the EEN group than in the non-EEN group $(P=0.001)$.

administration of steroids and immunosuppressants at the time of abscess diagnosis were not predictors for surgery.

Table 3 shows results of the final multivariable Cox proportional hazards regression analysis for surgery. All variables were fit in the same multivariable model. In this model, EEN (HR, 0.461; 95\% CI, 0.282-0.753; $P=0.002$ ) was associated with a decreased need for operation. Previous abdominal surgery (HR, 2.069; 95\% CI, 1.203-3.556; $P=0.009)$ and abscess diameter $>3 \mathrm{~cm}(\mathrm{HR}, 1.831 ; 95 \% \mathrm{CI}$, 1.092-3.071; $P=0.022)$ were significantly associated with an increased need for surgery.

3.4. Changes of the Serum Parameters and Outcomes in Patients Undergoing Surgery. Then, we compared the levels of albumin, erythrocyte sedimentation rate (ESR), and Creactive protein (CRP) at abscess diagnosis and at operation in both groups of patients who underwent surgery later. In the EEN group, the albumin level increased while ESR and CRP decreased remarkably after receiving preoperative EEN. In the non-EEN group, there were no significant differences of these parameters (Figure $2,{ }^{*} P<0.05,{ }^{* *} P<0.001$ ). We then investigated the differences of operative time, blood loss, stoma creation, postoperative IASCs, and postoperative hospital stay between the EEN and the non-EEN groups. The result shows that the risk of postoperative IASCs $(P=0.036)$ and duration of postoperative hospitalization $(P=0.032)$ were significantly decreased in the EEN group compared with the non-EEN group for patients undergoing surgery (Table 4).

\section{Discussion}

In the present study, we found that EEN could be safely used in $\mathrm{CD}$ patients with percutaneously undrainable abdominal abscesses. It has both the anti-inflammatory and nutritional effects, which may lead to abscess resolution and preoperative optimization and even avoidance of surgery.

The management strategy for spontaneous CD-related abdominal abscesses has traditionally been PD followed by elective surgery treating the underlying diseased intestine. Inaccessibility of abscess for image-guided PD made this intervention inapplicable in some patients. In the setting, antibiotics alone seems only effective for small abscesses
TABLE 2: Univariate analysis of potential predictors for surgery in $\mathrm{CD}$ patients with percutaneously undrainable abscesses.

\begin{tabular}{|c|c|c|}
\hline Variable & $\begin{array}{l}\text { 1-year cumulative } \\
\text { surgical rate (\%) }\end{array}$ & $P$ (log-rank) \\
\hline Gender & & 0.972 \\
\hline Male & 87.2 & \\
\hline Female & 83.3 & \\
\hline Age at diagnosis & & 0.895 \\
\hline A1 (16 years) & 0 & \\
\hline A2 (17-40 years) & 86.2 & \\
\hline A3 (40 years) & 84.0 & \\
\hline Disease location & & 0.208 \\
\hline L1 (ileal) & 85.7 & \\
\hline L2 (colonic) & 100.0 & \\
\hline L3 (ileocolonic) & 84.6 & \\
\hline Steroids use at diagnosis & & 0.703 \\
\hline No & 86.3 & \\
\hline Yes & 84.4 & \\
\hline AZA/6-MP use at diagnosis & & 0.550 \\
\hline No & 89.8 & \\
\hline Yes & 79.4 & \\
\hline Infliximab use at diagnosis & & 0.360 \\
\hline No & 87.7 & \\
\hline Yes & 70.0 & \\
\hline Perianal lesion & & 0.922 \\
\hline No & 85.5 & \\
\hline Yes & 85.7 & \\
\hline Previous abdominal surgery & & 0.007 \\
\hline No & 81.2 & \\
\hline Yes & 100.0 & \\
\hline Abscess diameter $>3 \mathrm{~cm}$ & & 0.006 \\
\hline No & 80.3 & \\
\hline Yes & 100 & \\
\hline Fistula & & 0.928 \\
\hline No & 85.4 & \\
\hline Yes & 85.7 & \\
\hline Multiple abscesses & & 0.060 \\
\hline No & 82.4 & \\
\hline Yes & 100 & \\
\hline Abscess location & & 0.253 \\
\hline Right lower quadrant & 83.8 & \\
\hline Pelvis & 88.0 & \\
\hline Others & 85.7 & \\
\hline Exclusive enteral nutrition & & 0.001 \\
\hline No & 96.6 & \\
\hline Yes & 79.6 & \\
\hline
\end{tabular}

AZA: azathioprine; 6-MP: mercaptopurine.

without associated fistula [15]. Most of the patients who failed the PD require surgery after a short period of time [16]. Unfortunately, the overall complication rate was 
TABLE 3: Multivariable Cox regression analysis of clinical factors associated with surgery in CD patients with percutaneously undrainable abscesses.

\begin{tabular}{lccc}
\hline Variable & Model coefficient & Hazard ratio (HR) & $95 \%$ CI \\
\hline Abscess diameter $>3 \mathrm{~cm}$ & 0.605 & 1.831 & $1.092-3.071$ \\
Previous abdominal surgery & 0.727 & 2.069 & $1.203-3.556$ \\
Exclusive enteral nutrition & -0.775 & 0.461 & 0.022 \\
\hline
\end{tabular}
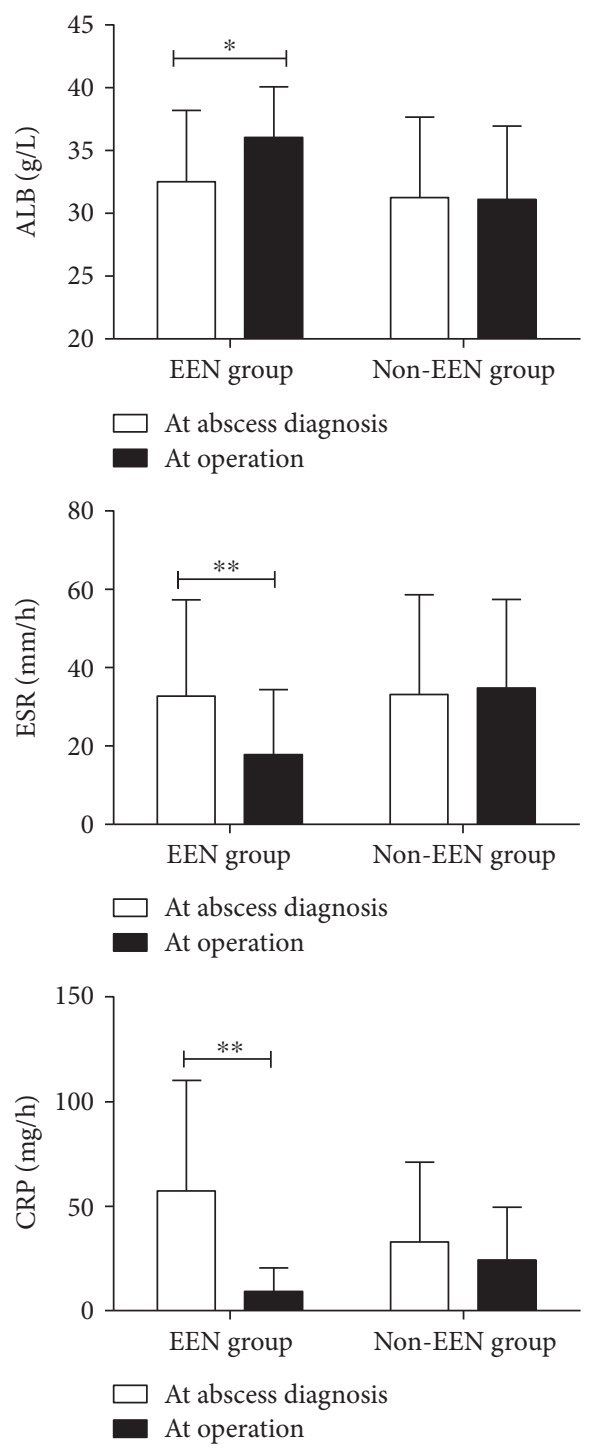

Figure 2: Comparison of the levels of albumin, erythrocyte sedimentation rate (ESR), and C-reactive protein (CRP) at abscess diagnosis and at operation in both groups of patients who underwent surgery later $\left({ }^{*} P<0.05,{ }^{* *} P<0.001\right)$.

significantly higher in patients undergoing initial or urgent surgery compared with those undergoing initial PD [17].

Enteral nutrition, a cheaper and safer treatment strategy, could be offered as an alternative option to treat CD [18]. EEN is able to reduce $\mathrm{CD}$ activity and maintain remission in both adults and children $[7-9,19]$. Numerous studies have found that preoperative EEN effectively relieves inflammatory bowel stricture and reduces the postoperative septic complications of fistulizing CD [11,20]. Li et al. [11] have found that the serum albumin level increases while CRR decreases remarkably in patients receiving preoperative EEN, which is in accordance with our findings. In a recent study, Heerasing et al. [10] found that EEN have the effect of decreasing the need for surgery in patients presenting with stricturing or penetrating complications of $C D$ disease and also have the value of reducing systemic inflammation and the incidence of postoperative IASCs. The results were also consistent with our finding. However, previous studies on the safety and efficacy of EEN in CD patients with abdominal abscesses are limited. We found here that EEN could optimize the patients' condition by improving the nutritional parameter, suppressing the inflammatory parameters. In addition, EEN postponed the definite surgery, improved the postoperative outcome and even avoided surgery.

Abscesses are usually associated with fistula or perforating complications, which leads to transmural translocation of bacteria from the diseased bowel to the contiguous tissue. Classically, for patients with abscess, oral feeding should be stopped to allow bowel rest, and logically conservative treatment with parenteral nutrition has been proposed as supportive therapy until the acute inflammation episode begins to resolve. In this situation, concern is raised about the aggravation of abdominal infection by enteral feeding. However, we demonstrate that EEN in patients with Crohn's abscess is safe. Most of the patients in the EEN group tolerated EEN, with only minor complications of diarrhea and abdominal floating in several cases. Fistulas were more common in the EEN group than in the nonEEN group, though the difference was not significant. In a previous study, fistula presence was associated with poor PD outcomes [21]. However, our results suggest that EEN is safe and tolerable in $\mathrm{CD}$ patients with concomitant abscess and fistula. It has the effects of both abscess resolution and concrescence of the fistula.

The precise mechanisms underlying the effect of enteral nutrition to cool down abscess are poorly understood. It might be multifactorial involving anti-inflammatory effects, mucosal healing stimulation, and intestinal microbiota modification [22, 23]. Apparently, a good nutritional status would theoretically lead to enhanced mucosal healing and systemic immune response [24]. Enteral nutrition has been shown to decrease intestinal permeability, which is associated with pathogenesis of CD [25]. Reduction in the workload of digestion and absorption by enteral nutrition may also play a role. Enteral nutrition might also change the intestinal flora participating in the development of inflammation in $\mathrm{CD}$, thus 
TABLE 4: Characteristics and postoperative short-term outcomes of patients requiring surgery.

\begin{tabular}{|c|c|c|c|}
\hline Characteristics and outcomes & EEN group $(n=46)$ & Non-EEN group $(n=28)$ & $P$ \\
\hline Gender, $n$ & & & 0.537 \\
\hline Male & 28 & 15 & \\
\hline Female & 18 & 13 & \\
\hline Montreal classification of age at abscess diagnosis, $n$ & & & 0.723 \\
\hline A1 (<16 years) & 0 & 0 & \\
\hline A2 (17-40 years) & 33 & 19 & \\
\hline A3 (>40 years) & 13 & 9 & \\
\hline Montreal classification of disease location, $n$ & & & 0.912 \\
\hline L1 (ileal) & 15 & 10 & \\
\hline L2 (colonic) & 2 & 1 & \\
\hline L3 (ileocolonic) & 29 & 17 & \\
\hline Previous surgical history, $n$ & 11 & 8 & 0.656 \\
\hline Multiple abscesses, $n$ & 8 & 7 & 0.430 \\
\hline Abscess location, $n$ & & & 0.636 \\
\hline Right lower quadrant & 20 & 13 & \\
\hline Pelvis & 16 & 7 & \\
\hline Others & 10 & 8 & \\
\hline Perianal lesion, $n$ & 6 & 7 & 0.219 \\
\hline Abscess diameter $>3 \mathrm{~cm}, n$ & 11 & 11 & 0.161 \\
\hline Fistula & 29 & 10 & 0.022 \\
\hline Steroids at diagnosis, $n$ & 14 & 14 & 0.092 \\
\hline AZA/6-MP at diagnosis, $n$ & 15 & 14 & 0.137 \\
\hline Infliximab at diagnosis, $n$ & 6 & 3 & 1.000 \\
\hline Surgical approach & & & 0.235 \\
\hline Open & 15 & 13 & \\
\hline Laparoscopy & 31 & 15 & \\
\hline \multicolumn{4}{|l|}{ Pre-op laboratory indices } \\
\hline White blood cell $\left(\times 10^{9} / \mathrm{L}\right)$, mean (range) & $6.45(2.4-24.4)$ & $6.28(3.8-14.9)$ & 0.836 \\
\hline Hemoglobin (g/L), mean (range) & $11.93(7.4-14.5)$ & $11.18(7.1-12.7)$ & 0.100 \\
\hline ESR (mm/h), mean (range) & $17.82(0-74)$ & $34.86(5-72)$ & $<0.001$ \\
\hline C-reactive protein $(\mathrm{mg} / \mathrm{L})$, mean (range) & $8.704(0-59.6)$ & $23.80(1.2-112.1)$ & 0.001 \\
\hline Albumin $(\mathrm{g} / \mathrm{L})$, mean (range) & $36.05(28.4-42.5)$ & $31.11(23.1-41.3)$ & $<0.001$ \\
\hline Abscess resolution, $n$ & 41 & 19 & 0.023 \\
\hline Post-op IASCs, $n$ & 3 & 7 & 0.036 \\
\hline Stoma creation, $n$ & 20 & 13 & 0.804 \\
\hline Postop hospital stay (days), mean $( \pm \mathrm{SD})$ & $9.65 \pm 6.75$ & $13.64 \pm 8.84$ & 0.032 \\
\hline Operative time $(\mathrm{min})$, mean $( \pm \mathrm{SD})$ & $203.63 \pm 69.04$ & $198.57 \pm 52.38$ & 0.740 \\
\hline Intraoperative bleeding $(\mathrm{ml})$, mean $( \pm \mathrm{SD})$ & $87.94 \pm 67.94$ & $86.07 \pm 57.18$ & 0.904 \\
\hline
\end{tabular}

IASCs: intra-abdominal septic complications; EEN: exclusive enteral nutrition; ESR: erythrocyte sedimentation rate; SD: standard deviation; AZA: azathioprine; 6-MP: mercaptopurine.

lowering the risks of bacterial translocation and subsequent infection [26].

Final Cox proportional hazards model in our study showed that abscess size $>3 \mathrm{~cm}$ and previous bowel resections increased the risk for surgery. This is not surprising. Large abscesses are always associated with more severe bowel diseases, leading to bowel obstruction and refractory abscesses. Riss et al. also found that previous resections for
CD were significant risk factors for reoperation primarily because of the more aggressive disease pattern in this group of patients [27].

There are also some limitations in our study. First, this was a retrospective study and the number of patients in this study was relatively small. Despite this, our results represent the only report on the use of EEN in CD complicated by percutaneously undrainable abdominal abscess. Obviously, 
further and larger prospective studies are required to verify the results. Secondly, there have been some patients that received the concomitant biological or immunosuppressant therapy after abscess resolution, which may have an impact on the patients' long-term outcomes, especially the rate of surgery. Despite this, the 1-year cumulative surgical rate was also significantly lower in the EEN group than in the non-EEN group. Finally, there have been a small number of patients that have withdrawn the EEN treatment before the surgery although all of them had abscess resolution, which may affect the patients' perioperative status and the surgical outcomes. Thus, a larger prospective study is required to define the optimal time interval between EEN and surgery in patients with abdominal abscesses.

In conclusion, the results of our study confirm that EEN is the treatment of choice in patients with percutaneously undrainable abdominal abscesses in $\mathrm{CD}$. It is effective to resolve abscess, improve nutritional status, and cool down the inflammation. Such a protocol is also associated with a reduced surgical rate and optimized preoperative condition as well as improved postoperative outcomes.

\section{Conflicts of Interest}

The authors declare that they have no conflicts of interest.

\section{References}

[1] J. Satsangi, M. S. Silverberg, S. Vermeire, and J. F. Colombel, "The Montreal classification of inflammatory bowel disease: controversies, consensus, and implications," Gut, vol. 55, no. 6, pp. 749-753, 2006.

[2] A. Yamaguchi, T. Matsui, T. Sakurai et al., "The clinical characteristics and outcome of intraabdominal abscess in Crohn's disease," Journal of Gastroenterology, vol. 39, no. 5, pp. 441-448, 2004.

[3] R. Muller-Wille, I. Iesalnieks, C. Dornia et al., "Influence of percutaneous abscess drainage on severe postoperative septic complications in patients with Crohn's disease," International Journal of Colorectal Disease, vol. 26, no. 6, pp. 769-774, 2011.

[4] L. A. Feagins, S. D. Holubar, S. V. Kane, and S. J. Spechler, "Current strategies in the management of intra-abdominal abscesses in Crohn's disease," Clinical Gastroenterology and Hepatology, vol. 9, no. 10, pp. 842-850, 2011.

[5] G. Cullen, B. Vaughn, A. Ahmed et al., "Abdominal phlegmons in Crohn's disease: outcomes following antitumor necrosis factor therapy," Inflammatory Bowel Diseases, vol. 18, no. 4, pp. 691-696, 2012.

[6] E. J. de Groof, F. Carbonnel, C. J. Buskens, and W. A. Bemelman, "Abdominal abscess in Crohn's disease: multidisciplinary management," Digestive Diseases, vol. 32, Supplement 1, pp. 103-109, 2014.

[7] C. L. Wall, A. S. Day, and R. B. Gearry, "Use of exclusive enteral nutrition in adults with Crohn's disease: a review," World Journal of Gastroenterology, vol. 19, no. 43, pp. 76527660, 2013.

[8] A. S. Day and R. N. Lopez, "Exclusive enteral nutrition in children with Crohn's disease," World Journal of Gastroenterology, vol. 21, no. 22, pp. 6809-6816, 2015.
[9] Z. Guo, R. Wu, W. Zhu et al., "Effect of exclusive enteral nutrition on health-related quality of life for adults with active Crohn's disease," Nutrition in Clinical Practice, vol. 28, no. 4, pp. 499-505, 2013.

[10] N. Heerasing, B. Thompson, P. Hendy et al., "Exclusive enteral nutrition provides an effective bridge to safer interval elective surgery for adults with Crohn's disease," Alimentary Pharmacology \& Therapeutics, vol. 45, no. 5, pp. 660-669, 2017.

[11] G. Li, J. Ren, G. Wang et al., "Preoperative exclusive enteral nutrition reduces the postoperative septic complications of fistulizing Crohn's disease," European Journal of Clinical Nutrition, vol. 68, no. 4, pp. 441-446, 2014.

[12] D. Yan, J. Ren, G. Wang, S. Liu, and J. Li, "Predictors of response to enteral nutrition in abdominal enterocutaneous fistula patients with Crohn's disease," European Journal of Clinical Nutrition, vol. 68, no. 8, pp. 959-963, 2014.

[13] D. L. Nguyen, W. J. Sandborn, E. J. Loftus et al., "Similar outcomes of surgical and medical treatment of intraabdominal abscesses in patients with Crohn's disease," Clinical Gastroenterology and Hepatology, vol. 10, no. 4, pp. 400-404, 2012.

[14] L. Zuo, Y. Li, H. Wang et al., "A practical predictive index for intra-abdominal septic complications after primary anastomosis for Crohn's disease: change in C-reactive protein level before surgery," Diseases of the Colon and Rectum, vol. 58, no. 8, pp. 775-781, 2015.

[15] F. Bermejo, E. Garrido, M. Chaparro et al., "Efficacy of different therapeutic options for spontaneous abdominal abscesses in Crohn's disease: are antibiotics enough?," Inflammatory Bowel Diseases, vol. 18, no. 8, pp. 1509-1514, 2012.

[16] L. M. A. Da, L. Stocchi, E. Tan, P. P. Tekkis, and V. W. Fazio, "Outcomes of Crohn's disease presenting with abdominopelvic abscess," Diseases of the Colon and Rectum, vol. 52, no. 5, pp. 906-912, 2009.

[17] X. He, X. Lin, L. Lian et al., "Preoperative percutaneous drainage of spontaneous intra-abdominal abscess in patients with Crohn's disease: a meta-analysis," Journal of Clinical Gastroenterology, vol. 49, no. 9, pp. e82-e90, 2015.

[18] J. Lee, R. Allen, S. Ashley et al., "British dietetic association evidence-based guidelines for the dietary management of Crohn's disease in adults," Journal of Human Nutrition and Dietetics, vol. 27, no. 3, pp. 207-218, 2014.

[19] J. K. Triantafillidis, C. Vagianos, and A. E. Papalois, “The role of enteral nutrition in patients with inflammatory bowel disease: current aspects," BioMed Research International, vol. 2015, Article ID 197167, 12 pages, 2015.

[20] D. Hu, J. Ren, G. Wang et al., "Exclusive enteral nutritional therapy can relieve inflammatory bowel stricture in Crohn's disease," Journal of Clinical Gastroenterology, vol. 48, no. 9, pp. 790-795, 2014.

[21] H. Lee, Y. H. Kim, J. H. Kim et al., "Nonsurgical treatment of abdominal or pelvic abscess in consecutive patients with Crohn's disease," Digestive and Liver Disease, vol. 38, no. 9, pp. 659-664, 2006.

[22] O. Ioannidis, I. Varnalidis, G. Paraskevas, and D. Botsios, "Nutritional modulation of the inflammatory bowel response," Digestion, vol. 84, no. 2, pp. 89-101, 2011.

[23] M. H. Alhagamhmad, A. S. Day, D. A. Lemberg, and S. T. Leach, "An update of the role of nutritional therapy in the management of Crohn's disease," Journal of Gastroenterology, vol. 47, no. 8, pp. 872-882, 2012. 
[24] P. A. Smith, "Nutritional therapy for active Crohn's disease," World Journal of Gastroenterology, vol. 14, no. 27, pp. 44204423, 2008.

[25] K. Teahon, P. Smethurst, M. Pearson, A. J. Levi, and I. Bjarnason, "The effect of elemental diet on intestinal permeability and inflammation in Crohn's disease," Gastroenterology, vol. 101, no. 1, pp. 84-89, 1991.

[26] G. Van Ooteghem, M. El-Mourad, A. Slimani et al., "Is early enteral nutrition dangerous in acute non surgical complicated diverticulitis? About 25 patients fed with oral fiber free energetic liquid diet," Acta Gastroenterologica Belgica, vol. 76, no. 2, pp. 235-240, 2013.

[27] S. Riss, I. Schuster, P. Papay, M. Mittlböck, and A. Stift, "Repeat intestinal resections increase the risk of recurrence of Crohn's disease," Diseases of the Colon and Rectum, vol. 56, no. 7, pp. 881-887, 2013. 


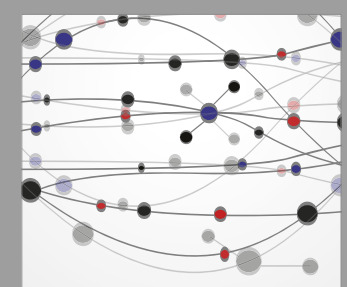

The Scientific World Journal
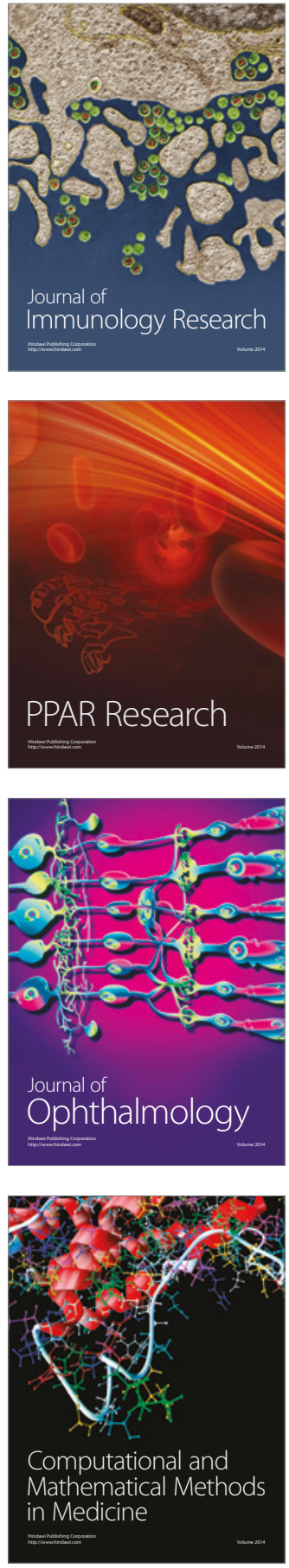

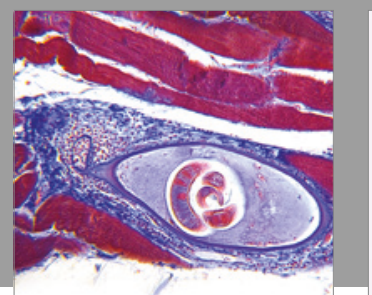

Gastroenterology Research and Practice
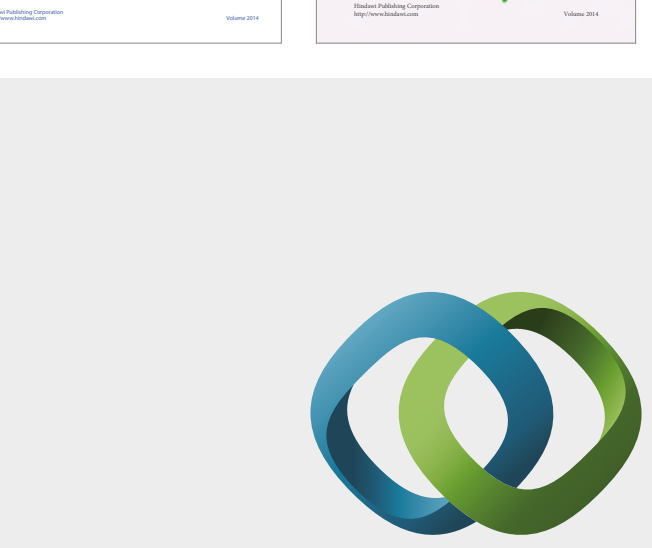

\section{Hindawi}

Submit your manuscripts at

https://www.hindawi.com
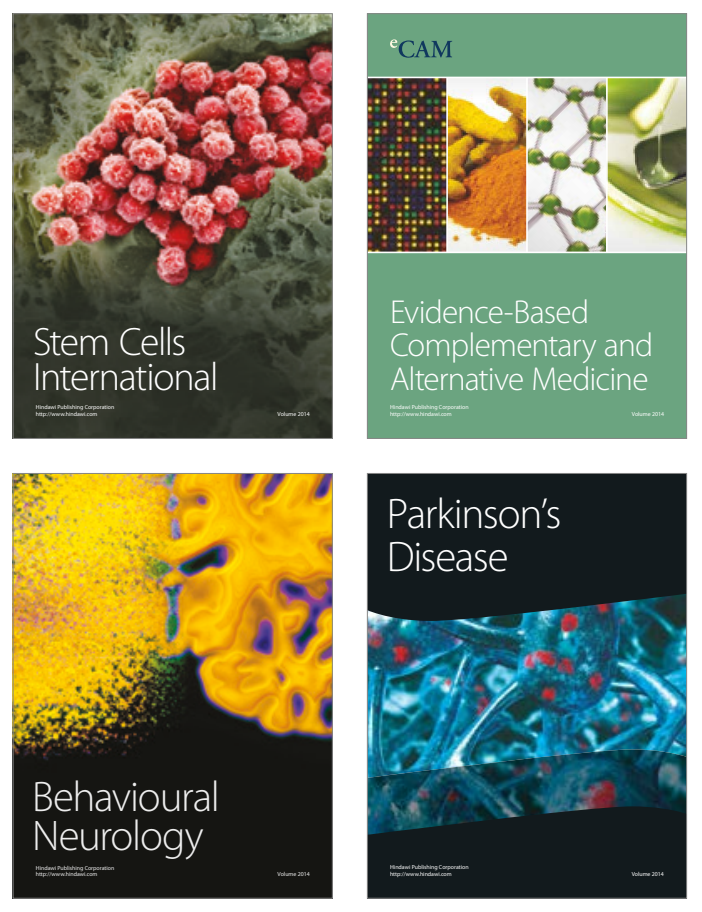
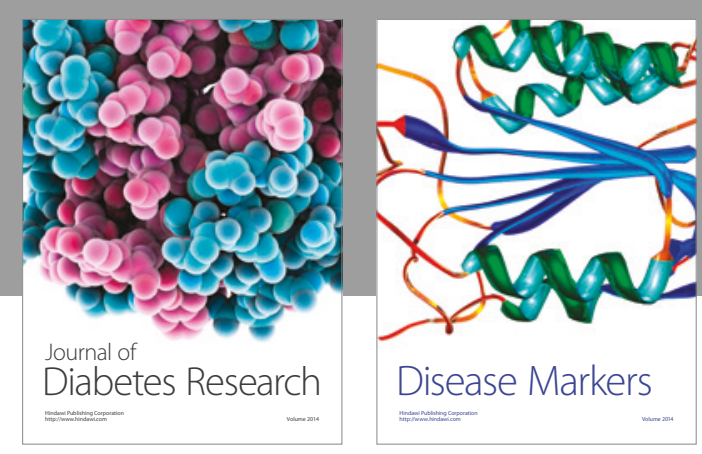

Disease Markers
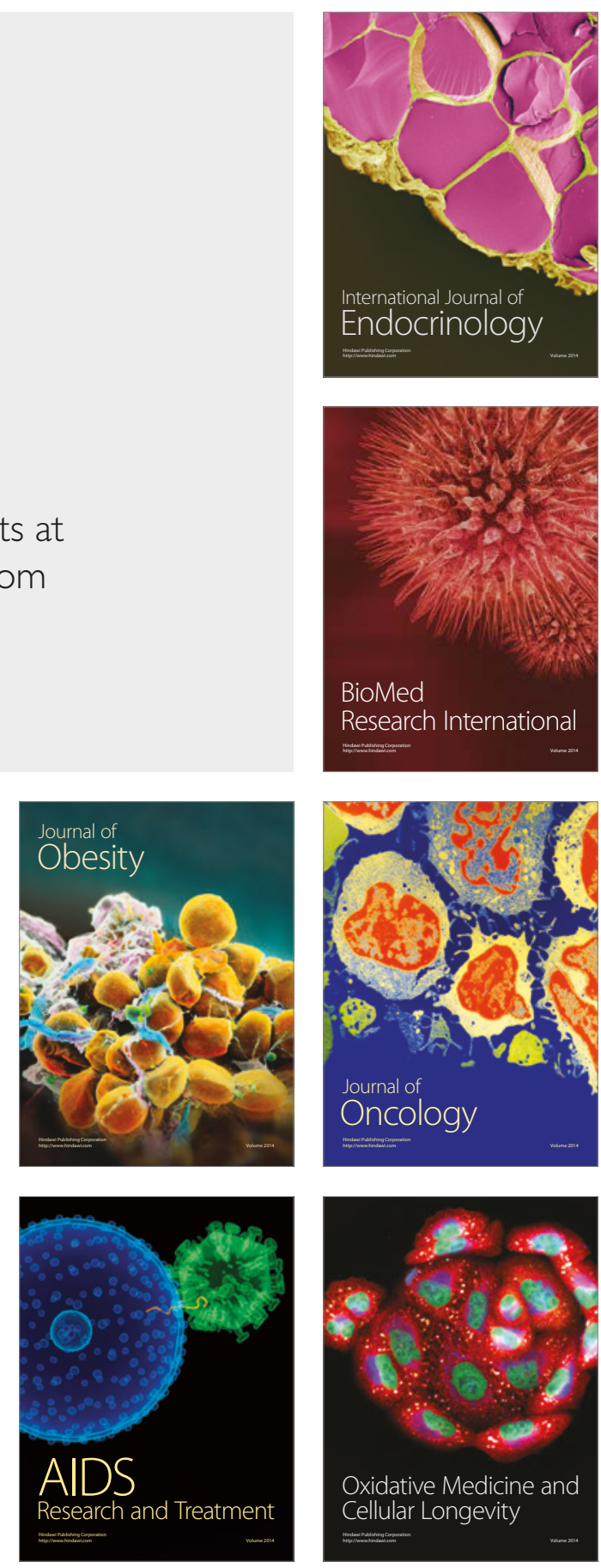